\title{
Long term evaluation of morphometric and ultrastructural changes of testes of alloxan-induced diabetic rats ${ }^{1}$
}

\author{
Amélia Arcângela Teixeira Trindade ${ }^{I}$, Antônio Caetano Pereira Simões ${ }^{\mathrm{II}}$, Reinaldo José Silva ${ }^{\mathrm{III}}$, Célia Sperandeo Macedo ${ }^{\mathrm{IV}}$, \\ César Tadeu Spadellav \\ IPhD, Assistant Professor, Department of Pediatrics, Faculty of Medicine, Brasilia University (UnB), Brasilia-DF, Brazil. Acquisition of data, technical \\ procedures, histological and ultrastructural analysis. \\ "PhD, Assistant Professor, Department of Pediatrics, Faculty of Medicine, São Paulo State University - UNESP, Botucatu, São Paulo, Brazil. Conception \\ and intellectual contributions to the study. \\ IIIPhD, Associate Professor, Department of Parasitology, Biosciences Institute, UNESP, Botucatu-SP, Brazil. Orientation in conduction of ultrastructural \\ study. \\ ${ }^{\text {IV }} \mathrm{PhD}$, Associate Professor, Department of Pediatrics, Faculty of Medicine, UNESP, Botucatu-SP, Brazil. Conception, design, analysis and interpretation \\ of data; manuscript preparation. \\ ${ }^{\mathrm{v}} \mathrm{PhD}$, Full Professor, Department of Surgery and Orthopedics, Faculty of Medicine, UNESP, Botucatu-SP, Brazil. Coordinating the study, manuscript \\ writing, critical revision, final approval of the version to be published.
}

\section{ABSTRACT}

PURPOSE: To evaluate in a long term the morphometric and ultrastructural changes in seminiferous tubules (ST) of normal and diabetic rats, and to correlate any changes with animal age and diabetes duration.

METHODS: Sixty male Wistar rats, three months-old, were randomly divided into two groups: 30 non-diabetic controls $(\mathrm{N})$ and 30 alloxan untreated diabetic (D). After one, six and 12 months of follow-up or diabetes induction rats were sacrificed and the testes examined. Morphometric measures of the ST were performed by digital imaging analysis. ST ultrastructure was analyzed by transmission electron microscopy.

RESULTS: Sustained hyperglycemic state was observed in all diabetic rats throughout the study. Serum testosterone was also significantly decreased in these animals. The diameter, total area, epithelium area and epithelium thickness of ST were lower and tubular density was higher in diabetic animals. Diabetic rats also showed ultrastructural changes compromising the whole testis including germ-, Sertoli-, and Leydig cells, and also the mithocondria and cellular nuclei. Most frequent of these consisted of vacuolization and/ or accumulation of lipid droplets and electron dense dark material in cell cytoplasm and/or in membranes, cellular degeneration, and apoptosis. Non-diabetic control rats also showed testicular lesions that resemble to the diabetic lesions, although much less severe and with later onset in life of these animals.

CONCLUSION: Histopathological changes observed in testes of normal and diabetic rats are closely related to the animal age and/ or duration of the hyperglycemic state, being progressively more severe in animals sacrificed belatedly. These changes may play an important role in male infertility observed in diabetic subjects.

Key words: Diabetes Mellitus. Alloxan. Infertility, Male. Spermatogenesis. Seminiferous Tubules. Microscopy, Electron. Rats. 


\section{Introduction}

Diabetes Mellitus (DM) is a chronic disease that affects millions of people worldwide and is associated with high morbidity and mortality ${ }^{1,2}$.

Abnormal sexual function in diabetic subjects suggests that the male gonads, like the kidneys, vessels, eyes, and nerves may also be affected by DM. This has been corroborated by studies demonstrating implications of diabetes on the endocrine control of spermatogenesis, spermatogenesis itself or on the penile erection and ejaculation ${ }^{3,4}$.

Alloxan or streptozotocin-induced diabetic rat have also shown morphological testicular lesions that affect practically all structures of the seminiferous tubules (ST), including Sertoli cells, spermatogonia, spermatocytes, spermatids, and spermatozoa ${ }^{5,6}$. Deleterious effects of DM have also noted in the Leydig cells, sexual behavior, sperm quantity and quality, and in neuroendocrinemale reproductive tract axis ${ }^{7-9}$.

However, with few exceptions the results of the most studies concerning the morphological and ultraestrutural changes in testes of diabetic animals are of short-term, being the course of the diabetic lesions accompanied during a period after diabetes onset of only weeks or months. Besides that the reported abnormalities are conflicting because studies have not always used rat samples matched for age and duration of exposure to the hyperglycemic state considered important factors to determine the severity of testicular lesions. So, the aim of this study was to assess the histopathological abnormalities of ST, and to correlate any changes with animal age and diabetes duration over a long period of follow-up up to 12 months of diabetes and 15 monthsold. We hope this knowledge can fill the gaps of the literature.

\section{Methods}

Sixty adult male Wistar rats, with approximately three months old, obtained from the Central Animal Laboratory, Faculty of Medicine - UNESP, Botucatu-SP, Brazil were used in this experiment. Use of laboratory animals followed the ethical code for animal experimentation of the Council for International Organization of Medical Sciences (CIOMS), and was approved by the Animal Experimentation Ethics Committee of our institution.

Animals were divided into two groups: Normal $(\mathrm{N})$ consisting of 30 healthy animals, non-diabetic controls; and Diabetic (D) consisting of 30 alloxan-induced diabetic animals without any treatment of the disease. Each group was further divided into three subgroups of ten animals and clinical and laboratory studies were performed at one, six and 12 months. Morphometric analysis of the testes was performed with one and six months, and ultrastructural studies at one, six and 12 months of normal follow-up or diabetes induction. At the time of sacrifice the animals of both groups were four, nine and 15 months-old, respectively.

Diabetes was induced by administration of an aqueous solution of alloxan at 2\% (5.6 dioxyuracil monohydrate - Sigma Co, USA) injected intravenously as a single dose of $42 \mathrm{mg} / \mathrm{kg}$ body weight. We only used animals with clinical signs of severe diabetes, fasting glucose $>250 \mathrm{mg} / \mathrm{dl}$ and urinary glucose $\geq 3000 \mathrm{mg} / \mathrm{dl}$ in two successive determinations (seven and 14 days after diabetes induction). Rats with mild diabetes or those who died throughout the experiment were replaced to avoid compromising the initial size of the sample.

Animals were sacrificed under general anesthesia using ketamine cloridrate at a dose of $100 \mathrm{mg} / \mathrm{kg}$ body weight, associated with xylazine at a dose of $25 \mathrm{mg} / \mathrm{kg}$ body weight, administered intramuscularly (Rhobifarma Ind. Farmacêutica, Hortolandia-SP). The blood collection at sacrifice was made by cardiac puncture, with the chest open. Euthanasia was by exsanguination volume, followed by the section of the vena cava infradiaphragmatic

The clinical parameters evaluated included: body weight $(\mathrm{g})$, water intake $(\mathrm{ml} / 24 \mathrm{~h})$, food intake $(\mathrm{g} / 12 \mathrm{~h})$ and urine volume ( $\mathrm{ml} / 24 \mathrm{~h})$. Laboratory included: blood and urinary glucose, glycosylated hemoglobin, plasma insulin and serum testosterone. Blood and urinary glucose were determined by standard enzymatic method (Johnson \& Johnson's - USA), glycosilated hemoglobin by agarose gel electrophoresis (Sebia, France), insulin by radioimmunoassay (Diagnostic Products Corporation, USA), and testosterone by electrochemiluminescence immunoassay (Roche Diagnostics, Germany). For the morphometric study of the seminiferous tubules (ST) the following variables were evaluated: tubular diameter $(\mu \mathrm{m})$, total tubular area $\left(\mu \mathrm{m}^{2}\right)$, epithelium germinal area $\left(\mu \mathrm{m}^{2}\right)$, lumen area $\left(\mu \mathrm{m}^{2}\right)$, epithelium germinal thickness $(\mu \mathrm{m})$, percentage of tubular lumen $(\%)$ or proportion of lumen area in relation to the total area, percentage of tubular epithelium (\%) or area of the epithelium in relation to the total area and density of ST/mm². For the ultrastructure of the ST it was emphasizing the aspects of spermatogonia, spermatids, Sertoli and Leydig cells and mitochondria, in relation to the presence or absence of: vacuolization, accumulation of waste materials and anomalous corpuscles in the cytoplasm and/or membranes cells, alterations in nuclear chromatin, cell degeneration and cell death. 


\section{Morphometric study}

The right testis of five normal non-diabetic rats and five untreated diabetic rats from each subgroup of animals, sacrificed at one and six months of follow-up or diabetes duration, was random collected and kept immersed in Bouin solution for 48 hours. After this period, fragments representing the whole gonad were sectioned, embedded in paraffin and processed and stained with hematoxylin-eosin for optical microscopy analysis.

The tissue was examined under an optical microscope connected to a computerized digital image system and data were analyzed using the software Qwin Lite 2.5 - LEICA, being selected the ST with well-defined and complete structures. For morphometric evaluations each structure was manually traced around it, outside of ST, and separately the tubule lumen using the computer mouse at magnification at $400 x$. For validation of the method all ST measures were performed by the two different investigators who were unaware of the experimental group to which the testes belonged. Images were captured from six to 15 sections per slide; and were randomly taken in the total testicle extension contained four to 25 tubules per section. From the total area of tubules and of the lumen, 101-195 ST were measured from each animal. The epithelium area obtained was given by the difference between those measurements.

The thickness of the seminiferous epithelium was measured from its base to its free surface on 68-135 tubules per animal. The tubular density was obtained by the numerical count of well-defined ST in the 10 first sections per animal previously filled in the computer, by counting 60 to 130 tubules per rat.

The percentage of lumen or proportion of the lumen area over total area was calculated by multiplying the lumen area by 100 and dividing the result by the sum of the lumen area and the germinal epithelium area. The calculations were made in 101 to 195 ST per animal. The percentage or proportion of epithelium of the germinal epithelium in relation to the total area was calculated using the same criteria to obtain the percentage of the lumen.

\section{Ultrastructural analysis}

The left testis of four normal non-diabetic rats and four untreated diabetic rats from each subgroup of animals, sacrificed at one, six and 12 months of follow-up or diabetes duration, was random cut into cylindrical pieces of $1 \mathrm{~mm}$ thick, fixed in $2.5 \%$ glutaraldehyde in phosphate buffer, $\mathrm{pH} 7.4$ for two hours $\left(0^{\circ} \mathrm{C}\right)$, post-fixed in $1 \%$ osmium tetroxide, washed in distilled water, incubated on uracyl acetate, dehydrated in acetone solutions and embedded in resin. Semithin cuts $(1 \mu \mathrm{m})$ were performed and ultrathin sections $(75 \mathrm{~nm})$ were stained with uranyl acetate and lead citrate and examined under a transmission electron microscope. Micrographs of 2-3 tubules were obtained from each subgroup of animals, and several regions from each tubule were examined.

At 5 - 7,000x magnification, five to ten electron micrographs were obtained from each tubule, identifying the Sertoli and Leydig cells, spermatogonia, spermatocytes, and spermatids, which were comparatively examined for the presence/ absence of vacuolization, electrondense material into mitochondria as well as the nuclei aspects of chromatin in regard of density and uniformity. At 10 - 20.000x magnification, the same structures were reviewed, and ten to 20 micrographs from each tubule were obtained for analysis and comparison. Mature spermatids were photographed at $20-40,000 x$ magnification.

In all micrographs obtained from tubules for each subgroup of animals an initial descriptive study was performed. Posteriorly, comparative descriptions were performed between normal and diabetic rats in the three follow-up periods (one, six and 12 months). All tests were performed by the same investigator who was unaware of the experimental group to which the material belonged.

\section{Statistical analysis}

The laboratory parameters of normal and diabetic groups were analyzed by nonparametric, ANOVA test, followed by the Dunn test of multiple comparisons; parametric variables were analyzed by Tukey test for multiple comparisons. The level of significance was $5 \%$ or $\mathrm{p}<0.05$. The morphometric parameters were analyzed by one way ANOVA, complemented by the Tukey test, adopting the standard $5 \%$ of significance or $\mathrm{p}<0.05$.

\section{Results}

\section{Clinical and laboratory findings}

Non-diabetic control rats $(\mathrm{N})$ had clinical and laboratory parameters compatible with those observed in animals of same strain and age at one, six and 12 months of follow-up. In contrast, untreated diabetic rats (D) had body weight gain lower than $\mathrm{N}$ animals, and significant increase of water and food intake and urine output $(\mathrm{p}<0.01)$. Blood and urinary glucose, and glycosylated hemoglobin were also significantly elevated in these rats in all periods. In contrast, untreated diabetic rats had insulin and serum 
testosterone levels significantly lower than $\mathrm{N}$ rats in all periods of follow-up ( $<<0.001)$. Results are showed in Tables 1 and 2.

TABLE 1 - Medians, maximun and minimun values of water intake (ml), and diuresis ( $\mathrm{ml})$ and means and standard deviations of the values of body weight $(\mathrm{g})$ and food intake $(\mathrm{g})$ of non-diabetic control $(\mathrm{N})$ and untreated diabetic (D) rats sacrificed at one, six and 12 months of follow-up or diabetes.

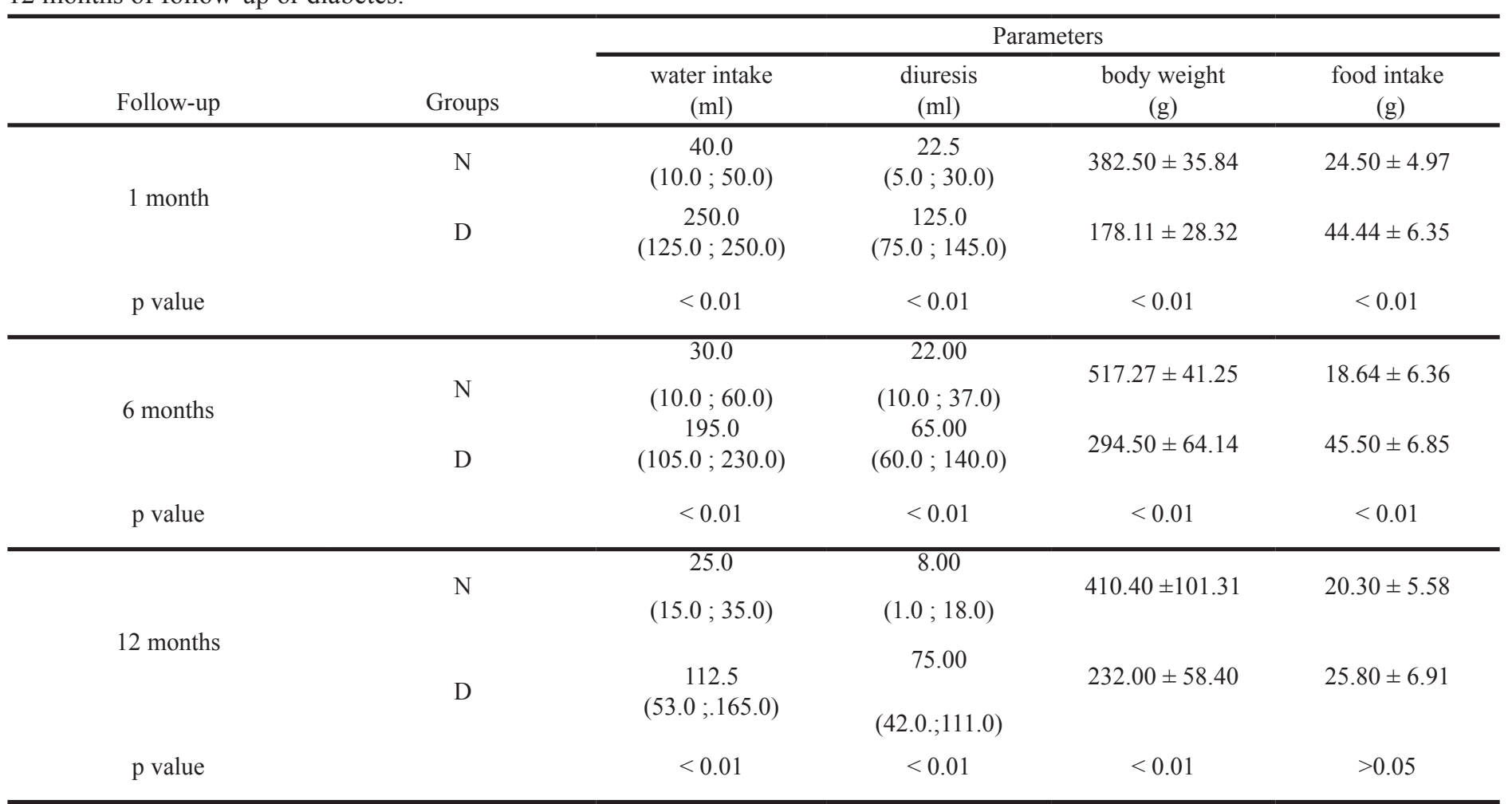

TABLE 2 - Means and standard deviations of the values of insulin ( $\mu \mathrm{IU} / \mathrm{ml})$, and glycosylated hemoglobin (\%) and medians, maximum and minimum values of blood glucose $(\mathrm{ml} / \mathrm{dL})$, and testosterone $(\mathrm{ng} / \mathrm{dl})$ of non-diabetic control $(\mathrm{N})$ and untreated diabetic (D) rats sacrificed at one, six and 12 months of follow-up or diabetes.

\begin{tabular}{|c|c|c|c|c|c|}
\hline \multirow[b]{2}{*}{ Follow-up } & \multirow[b]{2}{*}{ Groups } & \multicolumn{4}{|c|}{ Parameters } \\
\hline & & $\begin{array}{l}\text { Insulin } \\
(\mu \mathrm{IU} / \mathrm{ml})\end{array}$ & $\begin{array}{c}\text { glycosylated } \\
\text { hemoglobin (\%) }\end{array}$ & $\begin{array}{c}\text { blood glucose } \\
(\mathrm{ml} / \mathrm{dL})\end{array}$ & $\begin{array}{l}\text { testosterone } \\
(\mathrm{ng} / \mathrm{dl})\end{array}$ \\
\hline \multirow[t]{2}{*}{1 month } & $\mathrm{N}$ & $40.78 \pm 2.02$ & $3.24 \pm 0.97$ & $\begin{array}{c}122.5 \\
(80.0 ; 130,0)\end{array}$ & $\begin{array}{c}192.4 \\
(34.51 ; 269.0)\end{array}$ \\
\hline & $\mathrm{D}$ & $20.72 \pm 2.25$ & $9.54 \pm 1.33$ & $\begin{array}{c}640,0 \\
(564.0 ; 795.0)\end{array}$ & $\begin{array}{c}28.52 \\
(2.79 ; 86.1)\end{array}$ \\
\hline $\mathrm{p}$ value & & $<0.01$ & $<0.01$ & $<0.01$ & $<0.01$ \\
\hline \multirow[t]{2}{*}{6 months } & $\mathrm{N}$ & $42.49 \pm 2.64$ & $3.63 \pm 0.66$ & $\begin{array}{c}108.0 \\
(80.0 ; 125.0)\end{array}$ & $\begin{array}{c}65.53 \\
(37.48 ; 404.5)\end{array}$ \\
\hline & $\mathrm{D}$ & $18.56 \pm 6.75$ & $8.53 \pm 3.21$ & $\begin{array}{c}601.0 \\
(498.0 ; 963.0)\end{array}$ & $\begin{array}{c}23.20 \\
(8.62 ; 36.1)\end{array}$ \\
\hline $\mathrm{p}$ value & & $<0.01$ & $<0.01$ & $<0.01$ & $<0.01$ \\
\hline \multirow[t]{2}{*}{12 months } & $\mathrm{N}$ & $40.5 \pm 2.8$ & $4.0 \pm 0.8$ & $136.5(100.0 ; 168.0)$ & $\begin{array}{c}90.6 \\
(42.4 ; 193.4)\end{array}$ \\
\hline & $\mathrm{D}$ & $21.5 \pm 1.9$ & $10.4 \pm 1.8$ & $\begin{array}{c}379.5 \\
(254.0 ; 616.0)\end{array}$ & $\begin{array}{c}22.4 \\
(12.8 ; 47.5)\end{array}$ \\
\hline $\mathrm{p}$ value & & $<0.01$ & $<0.01$ & $<0.01$ & $<0.01$ \\
\hline
\end{tabular}




\section{Morphometric analysis}

The morphometric assessment showed that, compared with non-diabetic control rats $(\mathrm{N})$ (Figure 1A, C), all five testes analyzed of untreated diabetic animals (D) sacrificed at one and six months after diabetes onset presented a significant reduction of the germinal epithelium thickness (Figure 1B, D), which sometimes was completely atrophic (Figure 1F). In these animals, we observed vacuolization of the epithelium in many areas (Figure 1B, E). The diameter, total area, epithelium area and epithelium thickness of the ST were lower than those observed in N rats $(p<0.01)$. Tubular density and percentage of lumen was significantly higher in the $\mathrm{D}$ group with one and six months of follow-up $(\mathrm{p}<0.05)$. In contrast, the percentage of epithelium was lower $(p<0.01)$ (Table 3$)$. We also observed that morphological abnormalities found in $\mathrm{D}$ rats sacrificed at six months were more severe than those observed in rats sacrificed with one month of diabetes duration.

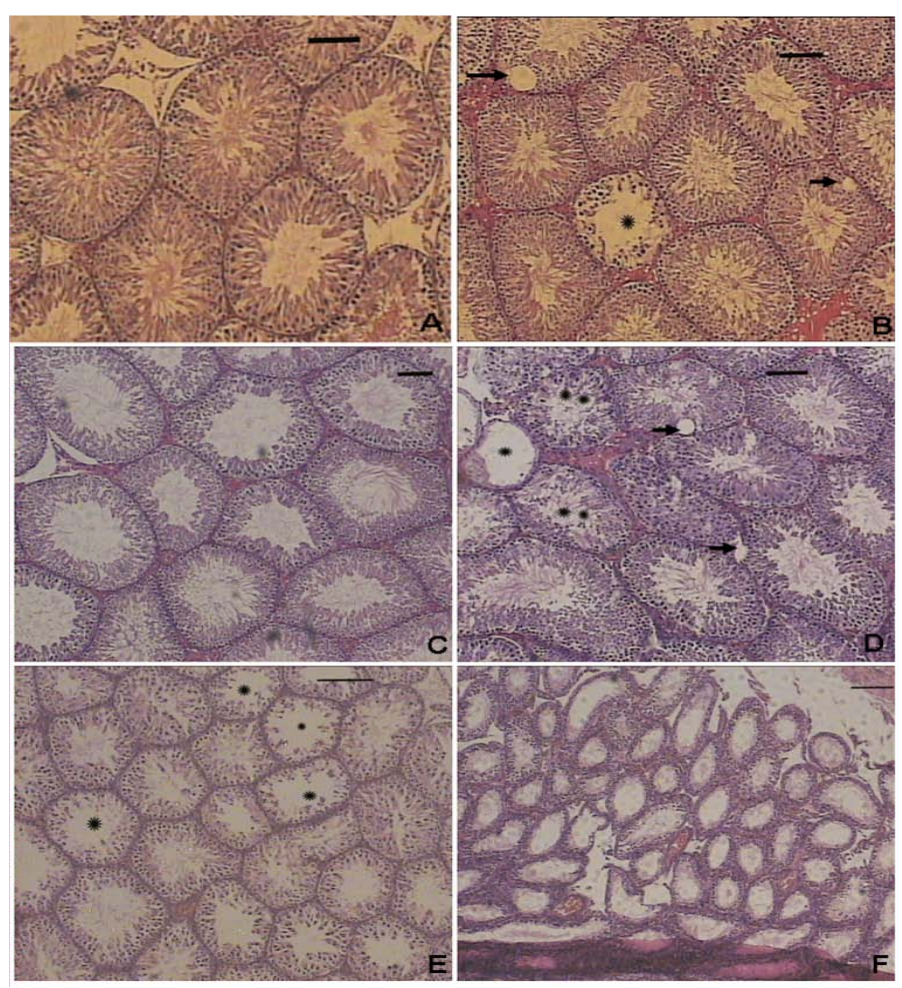

FIGURE 1 - Testes from the non-diabetic control (N) and untreated diabetic (D) rats (H\&E) showing seminiferous tubules (ST) of animals sacrificed with one and six months of follow-up or diabetes: A - ST of rat from the N Group with one month of follow-up without morphological changes; B - ST of rat from the D Group with one month of diabetes showing tubular diameter lower than that observed in $\mathrm{N}$ group rat plus vacuolization of the seminiferous epithelium (arrows) and epithelium atrophy (asterisk); C - Normal histology of ST in six months N group rat; D - Partial (double asterisks), complete atrophy (one asterisk), and vacuolization (arrows) of ST in six months D group rat; $\mathbf{E}$ - Intense atrophy of seminiferous epithelium in six months D group rat (asterisks); and $\mathbf{F}$ - Almost complete loss of the germinal epithelium (F) in six months $\mathrm{D}$ group rat. Bar $=100 \mu \mathrm{m}$.
TABLE 3 - Means and standard deviations of the total area $\left(\mu \mathrm{m}^{2}\right)$, lumen area, area of epithelium $\left(\mu \mathrm{m}^{2}\right)$, thickness of the epithelium $(\mathrm{mm})$, tubular number density $\left(\# / \mathrm{mm}^{2}\right)$, percentage $(\%)$ or proportion of lumen in relation to the total area, percentage (\%) of the epithelium or proportion of the epithelium in relation to the total area of seminiferous tubules of non-diabetic control $(\mathrm{N})$ and untreated diabetic (D) rats sacrificed at one and six months of follow-up or diabetes.

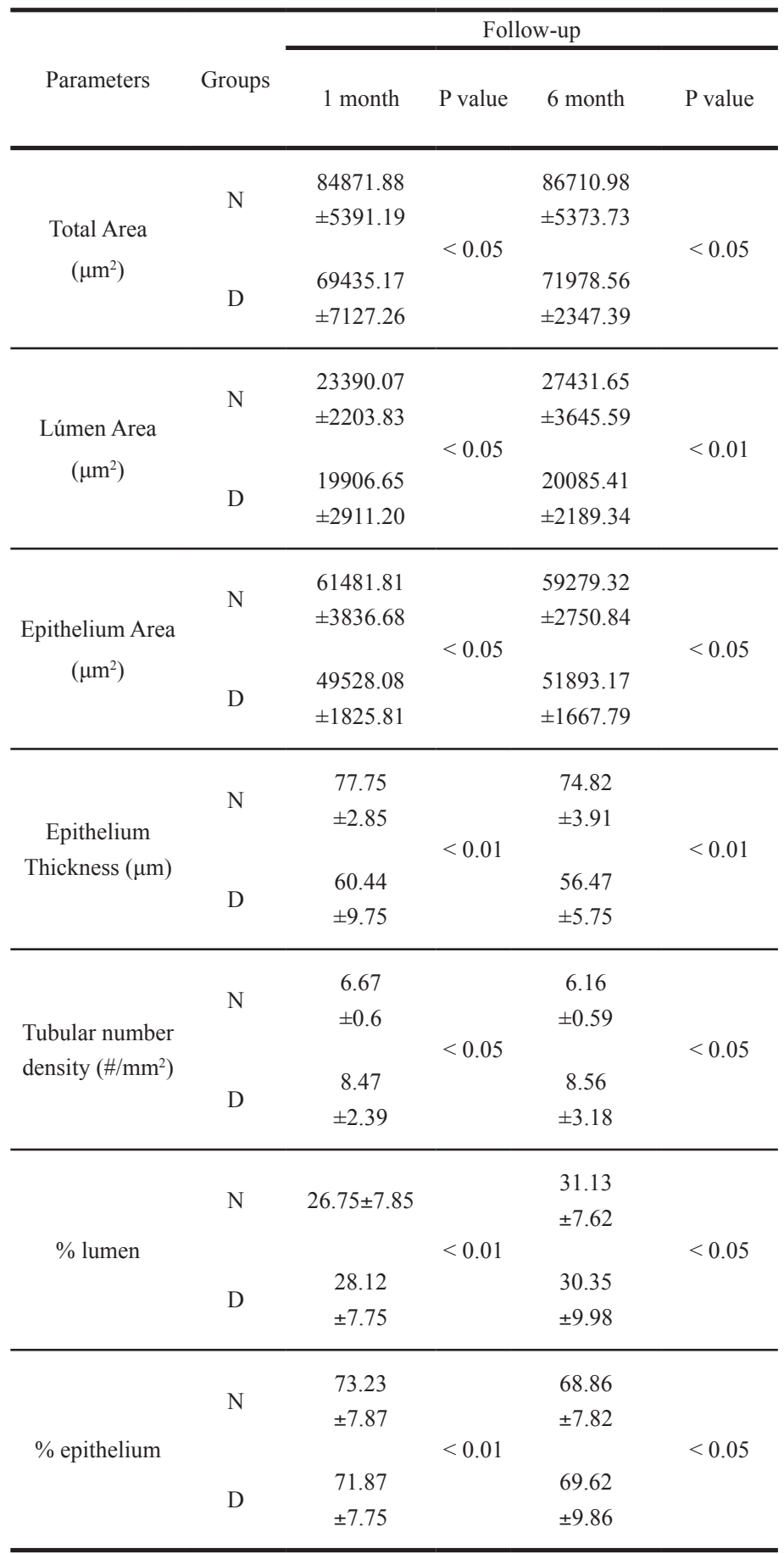




\section{Electron microscopy analysis}

All four testicles analyzed of the $\mathrm{N}$ group sacrificed at 1 month of follow-up showed Leydig cells of normal appearance and Sertoli cells with the characteristic nuclei and prominent nucleoli edentate; a large number of normal appearance spermatozoa were also found in the ST of these animals. In contrast, vacuoles were already detected in cytoplasm of the Sertoli cells and of spermatogonia of D rats sacrificed at 1 month of diabetes duration. In one animal of this subgroup, abnormality in the mitochondrial sheath was also found in all examined electronmicrographs.

At six months rats from the $\mathrm{N}$ group showed a large number of normal spermatozoa, with few of them showing defective mitochondria sheath, and some deposits of intracytoplasmic dark substance in cells that could be lipofuscin were found. However, in untreated diabetic rats from this subgroup a higher number of mitochondria were degenerative with fewer crests and electron dense accumulation in the membranes. In these animals there was vacuolization in cytoplasm of spermatogonia and in Sertoli cells. Spermatids had abnormal shape with less dense chromatin. Dense bodies with dark substance were found in greater quantities than in rats from the $\mathrm{N}$ group.

After 12 months, all sections examined in testes of $\mathrm{N}$ rats showed greater amount of dark substance deposits in the cell cytoplasm of spermatogonia, which was more dense and coarse than that observed with six month of follow-up. Similarly, most of the observed spermatozoa were normal, but, defects in dense fibers and in mitochondria sheath were more evident in the $\mathrm{N}$ group at 12 months than in six months. However, no apoptotic nuclei were observed in $\mathrm{N}$ rats in both periods. Ultrastructural changes of the testes, however, were more severe in D rats than those observed in $\mathrm{N}$ rats at 12 months of follow-up. Testicular lesions were also more severe in D rats sacrificed at 12 months than those observed in rats sacrificed at one and six months. At 12 months of diabetes, apoptotic nuclei characterized by dense nuclear chromatin were detected in spermatogonia and spermatocytes. Vacuolization in Sertoli cells cytoplasm was more severe. Leydig cells showed only slight accumulation of lipid droplets into the cytoplasm. Spermatozoa with defects in the dense fiber complex or in mitochondria or axoneme were more frequent. Accumulation of dark material, probably lipofuscin, forming dense deposits, accompanied by presence of intense cytoplasmatic vacuolization were also more abundant and severe on $12^{\text {th }}$ month of diabetes. Ultrastructural findings of non-diabetic and untreated diabetic rats are illustrated in Figures 2 and 3.
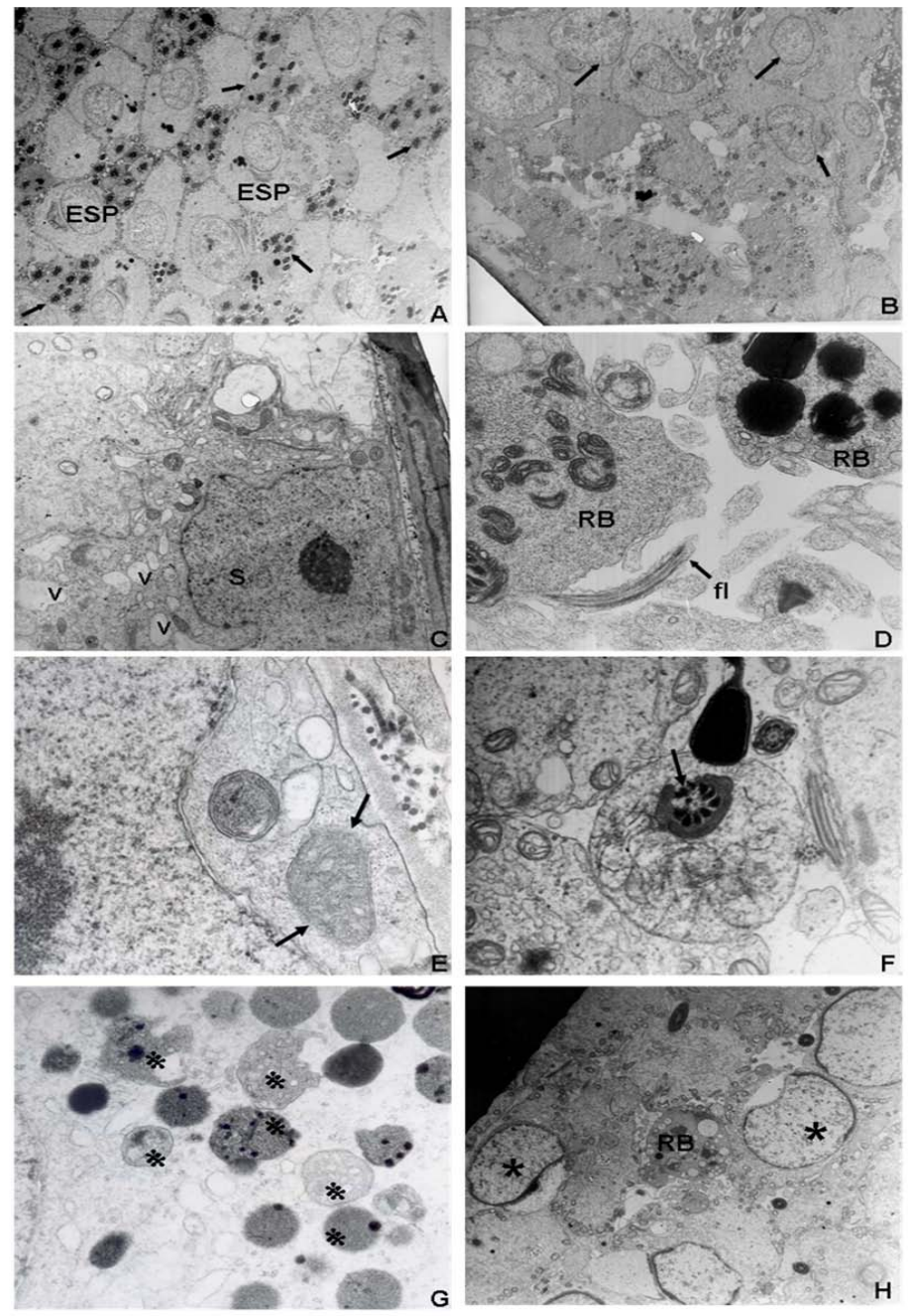

FIGURE 2 - Electromicrographs from the testes of non-diabetic control $(\mathrm{N})$ and untreated diabetic (D) rats sacrificed with one and six months of follow-up or diabetes showing: A - Normal spermatidis in stage I (ESP) and islands of spermatozoa (arrows) in rat from the $\mathrm{N}$ group with 1 month of follow-up (3.250x); B - Spermatidis in rat from the D group with 1 month of diabetes with few sperm (arrows) (2.450x); C - Sertoli cell (S) with vacuoles (v) in the cytoplasm in 1 month $\mathrm{D}$ group rat $(9.750 \mathrm{x})$; D Residual body (RB) in mitochondria with dark deposits, and flagellum (fl) in one month D group rat (42.000x); $\mathbf{E}$ - Mitochondria with irregular membrane (arrows) in six months D group rat (57.500x); F - Defective in dense fiber layer and absence of mitochondria sheath (arrow) of a spermatozoa in six months D group rat (23.000x); $\mathbf{G}$ - Altered shape and decreased number of crestis of mitochondria (asterisks) and accumulation of electron dense material in membranes (black bodies) in six months D group rat $(42.000 \mathrm{x}) ; \mathbf{H}$ - Round spermatids in transformation (asterisks) with modification of the acrosome plus residual body (RB) containing dense material and cellular debris in six months D group rat (4.350x). 

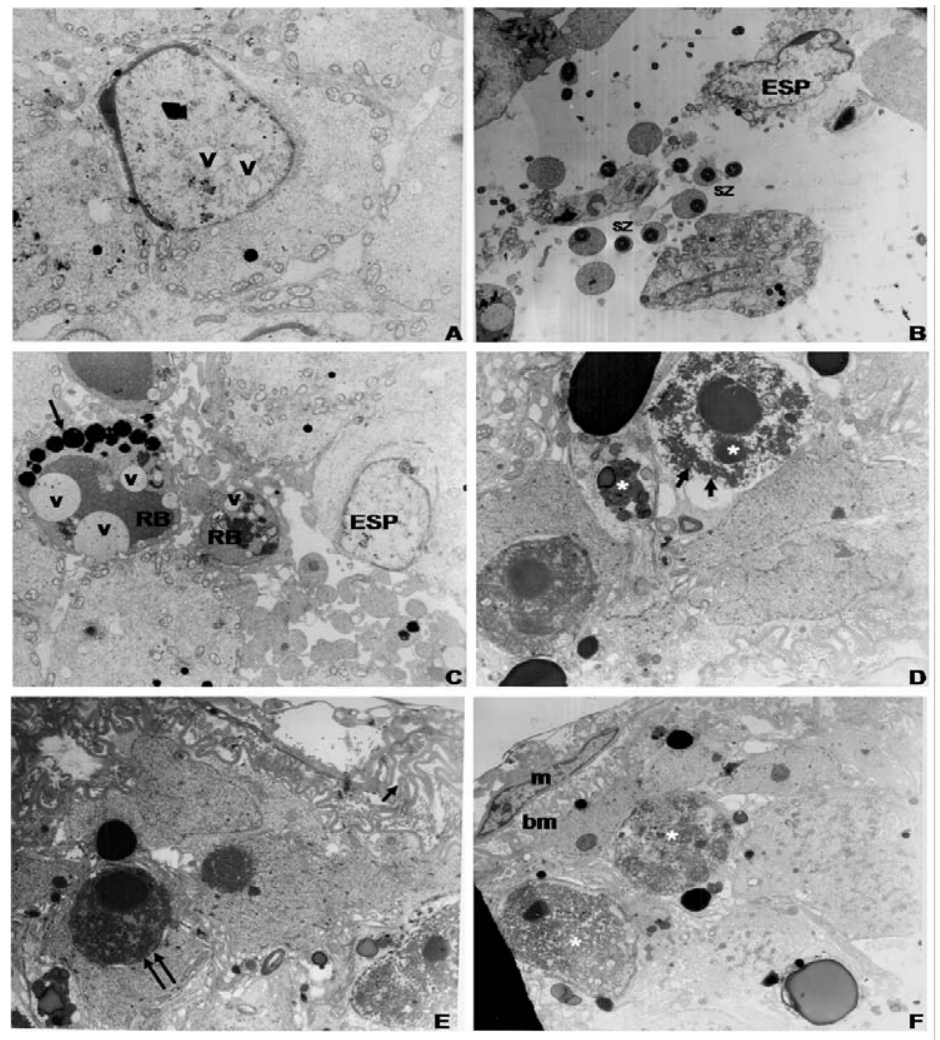

FIGURE 3 - Electromicrographs from the testes of untreated diabetic (D) rats sacrificed with 12 months of diabetes showing: $\mathbf{A}$ - Spermatocyte with vacuoles (v) in the nucleus with less dense chromatin $(3.250 \mathrm{x})$; B - Spermatid with acrosome (ESP) plus few spermatozoa (SZ) in the lumen (4.350x); C - Residual bodies (RB) with circular vacuoles (v) and dark substance (arrow) in the lumen plus spermatocyte with not evident acrosome and less dense chromatin (ESP) (5.750x); D - Two germ cells with masses of chromatin (asterisk) and deposits of dark granular substance (arrows) (5.750x); E - Spermatogonia degenerated (double arrows) with dark deposits and duplication and thickening of the basement membrane (one arrow) $(5.750 \mathrm{x}) ; \mathbf{F}$ - Two degenerated spermatocytes with very dense chromatin miode cells (m) and thickened basement membrane (bm). It is also observed the cell nuclei (asterisks) with intense alteration of chromatin which means nuclear degeneration (7.750x).

\section{Discussion}

Male sexual dysfunction has been described in subjects with diabetes mellitus (DM) as a consequence of its effects on the endocrine control of spermatogenesis, spermatogenesis itself or by impairing penile erection and ejaculation ${ }^{3,4}$. There are also a number of experimental reports in the literature examining the effects of diabetes on sexual behavior, sperm quantify and quality, and morphological testicular lesions ${ }^{5-9}$. However, with notable exceptions ${ }^{10-13}$ the results of those studies have been of short-term, being the course of the diabetic lesions accompanied during a period after diabetes onset of only weeks or months. Besides that the reported abnormalities are conflicting because studies have not considered the animal age and duration of exposure to the hyperglycemic state

In this study with long-term follow-up rats with 15 months of age and 12 months of diabetes showed morphological and ultrastructural lesions in the testes at various periods of sacrifice whose severity was directly related to the duration of diabetic state. It was also observed that age played an important role in the onset and progression of degenerative lesions of the testes since non-diabetic control rats also showed testicular lesions that resemble to the diabetic lesions, although much less severe and with later onset in life of these animals.

Wright et al. ${ }^{10}$ investigating the incidence of testicular lesions in spontaneously diabetic BB Wistar rats, non-diabetic siblings BB Wistar rats, and Wistar rats observed that testicular atrophy was the predominant finding in all three groups of rats after 254 days of follow-up. However, like us they also observed that atrophy occurred at a much younger age in the diabetic rats, and that there was a strong relationship between the duration of diabetes and the presence of atrophy, which was stronger than the relationship between age and atrophy. Testicular atrophy observed in the diabetic rats was also morphologically similar to the senile testicular atrophy in the non-diabetic rats.

Calvo et al. ${ }^{14}$ studying the reproductive ability in nondiabetic hamsters at various stages of life also concluded that the aging causes morphological alterations in the epididymis with significant consequences on the sperm quality. Wing and Christensen ${ }^{15}$ also observed that the morphometric measurements of the seminiferous tubules (ST) of non-diabetic Sprague-Dawley rats suffer variations related to the various stages of the cycle of spermiogenesis.

In our study we observed that the diameter, total area, epithelium area, and epithelium thickness of seminiferous tubules (ST) of untreated diabetic animals were significantly lower than that observed in non-diabetic control rats. As consequence ST density was increased in each testis analyzed. The germinal epithelium thickness of ST was also significantly reduced, and sometimes it was completely atrophic and vacuolized mainly in rats sacrificed after 6 months of diabetes onset. Guneli et al. ${ }^{16}$ studying the effect of melatonin on testicular damage in male rats with streptozotocin-induced diabetes observed reduction in ST diameter, increased thickening of the basement membrane in ST and degenerated germ cells after fourteen weeks and 6 days of diabetes onset. Ricci et al. ${ }^{6}$ while studying the morphological and functional alterations in the testes of rats injected with streptozotocin (STZ) at prepuperal and adult age also observed frequent abnormal histology, and altered seminiferous epithelium cytoarchitecture after 50 days after diabetes induction. The authors 
also concluded that altered spermatogenesis was more severe in diabetic rats at prepuperal age than adult age, although similar diminution in plasma testosterone levels was observed in both ages. This finding explains the great variation of results reported in literature involving the morphometric measurements of the testicular structure when animal age during diabetes induction is not observed.

In our study testosterone levels also remained diminished in diabetic rats from the first month of diabetes although the structure of Leydig cells appeared slightly altered in these animals only in rats sacrificed after 12 months of diabetes where only accumulation of intracytoplasmic lipid droplets were observed. This finding contrasts with that obtained by Orth et al. ${ }^{17}$ that reported a number of morphological changes in the Leydig cells from the testes of untreated streptozotocin-induced diabetic rats at two, three and four weeks after diabetes onset that included accumulation of lipid droplets, diminishing of smooth endoplasmic reticulum, and presence of several types of intracellular bodies. Among them, many resembled secondary lysossomes or dense bodies, while others appeared to be autophagic vacuoles. Myelinlike structures were also commonly observed within the cytoplasm of the Leydig cells or within mitochondria. The extracellular spaces surrounding Leydig cells also contained large accumulation of myelin-like material. In turn, Cameron et al. ${ }^{12}$ studying BBWOR rats with long-term hyperglycemia for a period greater than six months reported that despite significant reduction of total trunk testosterone the number of Leydig cells per testis was not different from similarly aged normoglycemic rats. Other hand, Murray et $a l .{ }^{11}$ observed that the aging also plays an important role on the function of Leydig cells of spontaneously diabetic BB rats, since low levels of testosterone were observed either in diabetics or normal control rats from the six months up to 16 months of follow-up. This finding was not observed in normal control rats of our study once the serum testosterone remained into normal levels all over the course of experiment.

We also observed that the ultrastructural changes of the testes were more severe in diabetic rats sacrificed after 12 months of diabetes than in those sacrificed after one and six months after disease onset. Most frequent of these consisted for intense vacuolization of the cytoplasm of Sertoli cells and sperrmatogonia, apoptotic nuclei with dense nuclear chromatin in spermatogonia and spermatocytes, higher number of degenerative mitochondria with fewer crests and electron dense accumulation in the membranes, and deposits of intracytoplasmic dark substance in cells that could be lipofuscin. Diabetic animals at 12 months of follow-up also showed greater amount of spermatidis and spermatozoa with defects in the dense fiber complex or in mithocondrial sheat or axoneme, which may reflect dysfunction of spermatogenesis caused by diabetes. These ultrastructural changes were also observed in analysis performed in testes of non-diabetic control rats, being more evident in older animals. This finding was not found by Syntin and Robaire ${ }^{18}$ in normal rats with 22 months old and by Calvo et al. ${ }^{14}$ in hamsters with 24 months.

According to Wei and $\mathrm{Kao}^{19}$ spermatids with defective mitochondria not only produce ATP less efficiently but also generate higher oxidative stress and decline of fertility. It is considered that the mitochondria are the main source of oxygen free radicals in cells and their dysfunction is closely related to changes caused by diabetes ${ }^{20}$.

Mitochondria comprise on average $15-22 \%$ of the total cell volume and produce $90 \%$ of the energy that is generated by oxidative phosphorylation resulting in the formation of $\mathrm{ATP}^{21}$. It has been found lower ATP production in the testes of rats after three months of diabetes accompanied for increased lipide peroxidation and reduction of glutathione peroxidase activity ${ }^{22}$.

Although mitochondrial function has been considered crucial for germ cells during the course of spermatogenesis ${ }^{21}$, with exception of a decrease in calcium load, several aspects of mithocondrial function evaluated in testes of untreated streptozotocin-induced diabetic rats, including respiratory and electric potential function, failed to reveal severe testicular mithocondrial dysfunction ${ }^{23}$. In our opinion, however, the short follow-up time of the diabetic rats in this study may explain why disorders were not detected in mitochondrial function.

Therefore, we believe that severe disruption of spermatogenesis resulting in abnormal spermatids observed in our diabetic rats after six and 12 months of diabetes are probably due to progressive mitochondrial dysfunction caused by diabetes. This impression is corroborated by others ${ }^{24}$ that consider that the onset and severity of diabetes is directly or indirectly influenced by mitochondrial deficiencies or dysfunction.

Degeneration and cell death in spermatogonia and spermatocytes seen in our diabetic rats at 12 months after induction of diabetes, with appearance of late apoptosis were similar to those found in mice, nonobese diabetic, four to five months in phase of insulate $^{25}$. By using a test that involves deoxinucleotidiltransferase (tunel assay), apoptosis can be detected in $3-6$ months after diabetes induction ${ }^{13,16}$.

The conditions for cell death by apoptosis in rat testis are low levels of testosterone, radiation and toxic substances ${ }^{26}$. Apoptosis was probably triggered by the association of testosterone deprivation with oxidative stress for long periods in germ cells. 
The oxidative stress is determined by hyperglycemia which causes a reduction of endogenous antioxidants and an increasing of superoxide, hydroxyl, and peroxyl production with injury of the cellular DNA and proteins ${ }^{27}$.

Sertoli cells showed vacuolization from 1 month after diabetes induction. These cells are necessary for spermatogenesis for producing substances to the germ cells survival and produce an essential environment for adequate spermatogenesis ${ }^{28}$. One may speculate that the vacuolization of these cells disturbed its role in providing nutrients and regulatory factors to germ cells with the consequence of altered spermatogenesis with a larger number of spermatozoa with defects and lower spermatozoa number.

The dark substance accumulation in the cytoplasm and residual bodies may be lipofuscin, an insoluble pigment composed of lipids polymers, phospholipids complexes with metals and protein resulting from lipid peroxidation, which increases with age in cells ${ }^{29}$. Similar lipofuscin accumulation was described by Calvo et al. ${ }^{14}$ in the epididymis of normal hamsters with 24 months of age.

The autophagy of mitochondria appears to be the main factor for the formation of lipofuscin, and oxidative stress has obvious effects on lipofuscinogenesis. Cell injury by accumulation of lipofuscin arises due to the large amount of iron, which facilitates the generation of oxygen free radicals causing lysosome damage and destabilization of the cell by releasing free radicals or enzymes hidrolases ${ }^{29}$. It was suggested that this accumulation reduces the cellular protein turnover and the half-life of mitochondria causing degeneration and cell death ${ }^{30}$.

\section{Conclusions}

Diabetes causes directly or indirectly progressive impairment on Sertoli cells and germ cells, a decrease of testosterone levels and altered spermatogenesis, evidenced by spermatozoa defective. These changes increase with the length of the diabetic state, and with the animal aging, and they end up with coarse deposits of lipofuscin in cells, which accelerate cell degeneration culminating in cell death. These changes may play an important role in male infertility observed in diabetic subjects.

\section{References}

1. Wild S, Roglic G, Green A, Sicree R, King H. Global prevalence of diabetes. Estimates for the year 2000 and projections for 2030. Diabetes Care. 2004;27(5):1047-53.

2. World Health Organization (WHO). Health topics: Diabetes. Available from: http://www.who.int/topics/diabetes_mellitus/en/

3. Sexton WJ, Jarow JP. Effect of diabetes mellitus upon male reproductive function. Urology. 1997;49(4):508-13.

4. Agbaje IM, Rogers DA, McVicar CM, McClure N, Atkinson AB, Mallidis C, Lewis SEM. Insulin dependent diabetes mellitus: implications for male reproductive function. Hum Reprod. 2007;22(7):1871-7.

5. Schöffling K, Federlin K, Schmitt W, Pfeiffer EF. Histometric investigations on the testicular tissue of rats with alloxan diabetes and Chinese hamsters with spontaneous diabetes. Acta Endocr. 1967;54(2):335-46.

6. Ricci G, Catizone A, Esposito R, Pisanti FA, Vietri MT, Galdieri M. Diabetic rat testes: morphological and functional alterations. Andrology. 2009;41(6):361-8.

7. Sanguinetti RE, Ogawa K, Kurohmaru M, Hayashi Y. Ultrastructural changes in mouse Leydig cells after streptozotocin administration. Exp Anim. 1995;44(1):71-3.

8. Scarano WR, Messias AG, Oliva SU, Klinefelter GR, Kempinas WG. Sexual behavior, sperm quantity and quality after short-term streptozotocin - induced hyperglycaemia in rats. Int $\mathrm{J}$ Androl. 2006;29(4):482-8.

9. Seethalakshmi L, Menon M, Diamond D. The effect of streptozotocininduced diabetes on the neuroendocrine-male reproductive tract axis of the adult rat. J Urol. 1987;138(1):190-4.

10. Wright JR, Yates AJ, Sharma HM, Shim C, Tigner RL, Thibert P. Testicular atrophy in the spontaneously diabetic BB Wistar rat. Am J Pathol. 1982;108(1):72-9.

11. Murray FT, Cameron DF, Orth JM. Gonadal dysfunction in the spontaneously diabetic BB rat. Metabolism. 1983;32(7 Suppl 1):141-7.

12. Cameron DF, Rountree J, Schultz RE, Repetta D, Murray FT. Sustained hyperglycemia results in testicular dysfunction an reduced fertility potential in BBWOR diabetic rats. Am J Phisiol. 1990;259(6):E881-E9.

13. Cai L, Chen S, Evans T, Deng DX, Mukherjee K, Chakrabarti S. Apoptotic germ-cell death and testicular damage in experimental diabetes: prevention by endothelin antagonism. Urol Res. 2000;28(5):342-7.

14. Calvo A, Pastor LM, Martínez E, Vázquez JM, Roca J. Age-related changes in the hamster epididymis. Anat Rec. 1999;256(4):335-46.

15. Wing TY, Christensen AK. Morphometric studies on rat seminiferous tubules. Am J Anat. 1982;165(1):13-25.

16. Guneli E, Tugyan K, Ozturk H, Gumustekin M, Cilaker S, Uysal N. Effect of melatonin on testicular damage in streptozotocin-induced diabetic rats. Eur Surg Res. 2008;40(4):354-60.

17. Orth JM, Murray FT, Bardin CW. Ultrastructural changes in Leydig cells of streptozotocin - induced diabetic rats. Anat Rec. 1979;195(3):415-30.

18. Syntin P, Robaire B. Sperm, structural changes and mobility during aging in Brown Norway rat. J Androl. 2001;22(2):235-44.

19. Wei YH, Kao SH. Mitochondrial DNA mutation and depletion are associated with decline of fertility and mobility of human sperm. Zool Stud. 2000;39:1-12.

20. Rolo AP, Palmeira CM. Diabetes and mitochondrial function: role of hyperglycemia and oxidative stress. Toxicol Appl Pharmacol. 2006;212(2):167-78.

21. Meinhardt A, Wilhelm B, Seitz J. Expression of mitochondrial marker proteins during spermatogenesis. Hum Reprod Update. 1999;5(2):108-19.

22. Amaral S, Moreno AJ, Santos MS, Seiça R, Ramalho-Santos J. Effects of hyperglycemia on sperm and testicular cells of GotoKakizaki and streptozotocin-treated rat models for diabetes. Theriogenology. 2006;66(9):2056-67.

23. Amaral S, Mota PC, Lacerda B, Alves M, Pereira ML, Oliveira PJ, 
Ramalho-Santos J. Testicular mitochondrial alterations in untreated streptozotocin-induced diabetic rats. Mitochondrion. 2009;9(1):4150 .

24. Gerbitz KD, van den Ouwenland JM, Maassen JA, Jaksch M Mithocondrial diabetes mellitus: a review. Biochim Biophis Acta. 1995;127(1):253-60.

25. Sainio-Pöllänen S, Henriksén K, Parvinen M, Simell O, Pöllänen P. Stage specific degeneration of germ cells in the seminiferous tubules of non-obese diabetic mice. Int J Androl. 1997;20(4):243-53.

26. Henriksén K, Kulmala J, Toppari J, Mehrotra K, Parvinen M. Stagespecific apoptosis in the rat seminiferous epithelium: quantification of irradiation effects. J Androl. 1996;17(4):394-402.

27. Sinha Hikim AP, Swerdloff RS. Hormonal and genetic control of germ cells apoptosis in the testis. J Reprod. 1999;4(1):38-47.

28. Griswold MD. Interactions between germ cells and Sertoli cells in the testis. Biol Reprod. 1995;52(2):211-6.

29. Brunk UT, Terman A. Lipofuscin: Mechanisms of age-related accumulation influence on cell function and free radical. Free Radic Biol Med. 2002;33(5):611-9.

30. von Zglinicki T, Nilsson E, Döcke WD, Brunk UT. Lipofuscin accumulation and ageing of fibroblasts. Gerontology. 1995;41(Suppl. 2):95-108.

\section{Acknowledgments}

To Mauro Masson Lerco by laboratorial assistance in the ultrastructural study, Patricia Pintor Reis for reviewing the text translated into English and Erika Veruska Ortolan for their valuable suggestions.

\section{Correspondence:}

César Tadeu Spadella

Faculdade de Medicina de Botucatu, Departamento de Cirurgia e Ortopedia

Campus da UNESP

Distrito de Rubião Jr., s/n Anexo Verde

18618-970 Botucatu - SP Brasil

Tel.: (55 14)3880-1447

spadella@fmb.unesp.br

Received: December 11, 2012

Review: February 13, 2013

Accepted: March 14, 2013

Conflict of interest: none

Financial source: Sao Paulo Research Foundation (FAPESP)

${ }^{1}$ Research performed at Experimental Surgery Laboratory, Faculty of Medicine, Sao Paulo State University (UNESP), Botucatu-SP, Brazil. Part of $\mathrm{PhD}$ degree thesis, Postgraduate Program in General Basis of Surgery. Tutor: Célia Sperandeo Macedo. 